DOE/PC/89800 - T2

-

$\mathrm{DOE} / \mathrm{PC} / 89806--\mathrm{T} 2$

$F E B,{ }_{1902}$

DE92 007758

CONFINED VORTEX SCRUBBER

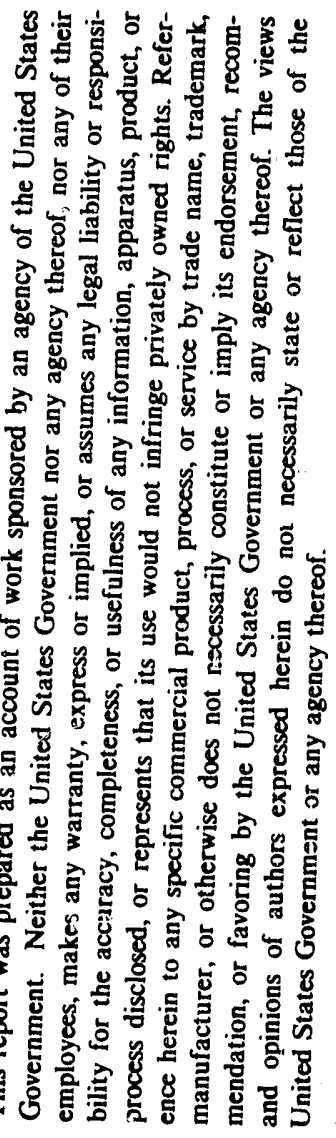

QUARTERLY TECHNICAL PROGRESS REPORT

for the period

October 1, 1989 - December 31, 1989

Date Prepared

February 1990

Prepared by

AVCO RESEARCH LABORATORY

2385 Revere Beach Parkway

Everett, Massachusetts 02149

\author{
Prepared for \\ U.S. DEPARTMENT OF ENERGY \\ Pittsburgh Energy Technology Center \\ Pittsburgh, Pennsylvania 15236
}

Under Contract No. DE-AC22-89PC89806 
TABLE OF CONTENTS

1.0 SUMMARY $\ldots \ldots \ldots \ldots . \ldots \ldots \ldots$

2.0 TECHNICAL APPROACH ........................ 4

2.1 PROGRAM OBJECTIVE ...................... 4

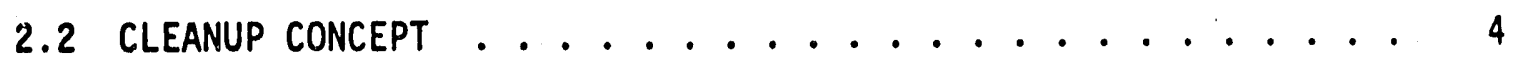

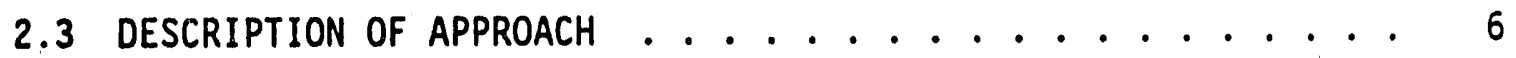

3.0 TECHNICAL PROGRESS ............................. 10

3.1 TASK 2: DESIGN EXPERIMENT ............... 10

3.1 .1 CVs Design Concept ............ . . 10

3.1 .2 CVS Design Details .............. 12

3.1.3 Experimental Arrangement . . . . . . . . 18

3.2 TASK 3: FABRICATE EXPERIMENT .................. 21

3.3 TASK 4: VORTEX FLOW EXPERIMENTS ............. 21

3.3.1 Shakedown Experiments ........... 23

3.3.2 Aerodynamic Tests . . . . . . . . . 25

3.3.3 Water Addition Tests ............ 30

4.0 CONCLUSION AND PLANS FOR FUTURE WORK . . . . . . . . . 33

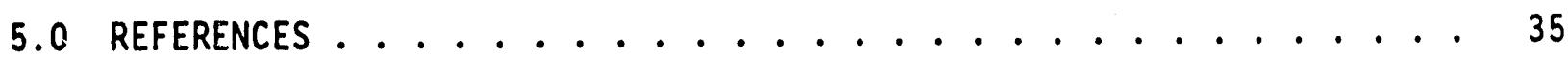




\subsection{SUMMARY}

The program objective is to demonstrate efficient removal of fine particulates to sufficiently low levels to meet proposed small scale coal combustor emission standards. This is to be accomplished using a novel particulate removal device, the Confined Vortex Scrubber (CVS). The CVS consists of a cylindrical vortex chamber with tangential flue gas inlets. The clean gas exit is via tangent slots in a central tube. Liquid is introduced into the chamber and is confined within the vortex chamber by the centrifugal force generated by the gas flow itself. This confined liquid forms a layer through which the flue gas is then forced to bubble, producing a strong gas/liquid interaction, high inertial separation forces and efficient particulate cleanup. In effect, each of the sub-millimeter diameter gas bubbles in the liquid layer acts as a micro-cyclone, inertially separating particles into the surrounding liquid. The CVS thus obtains efficient particle removal by forcing intimate and vigorous interaction between the particle laden flue gas and the liquid scrubbing medium.

In order to demonstrate and optimize the cleanup performance of the CVS, a twelve month experimental program supported by analytical efforts is being carried out. Tests are being conducted on a model CVS at a mass flow equivalent to the exhaust gas flow of a $1 \mathrm{MM} \mathrm{Btu/hr}$ combustor. The test gas is essentially at ambient temperature and pressure. This is a report of technical progress during the first quarter of this program.' During this quarter, a cVS configuration was defined and the experiment was fabricated and installed at ARL's Haverhill, Massachusetts test facility. Vortex flow experiments were 
commenced.

A CVS design geometry and a number of parametric variations have been defined and the necessary hardware has been designed and fabricated. A modular design approach has been adopted in order to allow rapid and simple modification of the CVS chamber aspect ratio and of air and water inlet and outlet geometries. The experimental hardware has been assembled and installed at ARL's Haverhi11, Massachusetts test facility.

Initial aerodynamic testing of the CVS experimental hardware indicated that the CVS slot exit tube design produced significantiy lower pressure drops that a conventional vortex finder type exit tube. The exit tube size was also demonstrated to have a dramatic effect on device pressure drop. Changing the exit tube diameter from one half to one quarter of the main chamber diameter producing a tripling of the device pressure drop. Reducing the slot height of the air inlet was also found to reduce the non-dimensional pressure drop of the device. Further refinements in system design progressively reduced the device pressure drop to less than half that of a conventional reverse flow cyclone separator operating at the same inlet velocity.

Preliminary water addition experiments indicated that a sheet of water could indeed be established and contained within the chamber and that the proposed water removal mechanism via the chamber end-wall secondary flows was effective. However, some of the input water is being lost via the clean gas exit. The mechanism responsible for this loss is related to management of the water flow in the water out-take chamber.

To date only one chamber aspect ratio and one air inlet type has been tested. Further tests will examine the perforniance of a lower aspect ratio chamber and of jet inlets. In addition the water loss mechanism will be 
examined in detail and methods of eliminating the loss will be developed and tested. 


\subsection{TECHNICAL APPROACH}

\subsection{PROGRAM OBJECTIVE}

The program objective is to demonstrate efficient removal of fine particulates to sufficiently low levels to meet proposed small scale coal combustor emission standards. This is to be accomplished using a novel particulate removal device, the Confined Vortex Scrubber. This is the first quarterly technical progress report under this contract. Accordingly, a summary of the cleanup concept and the structure of the program is given here.

\subsection{CLEANUP CONCEPT}

The development of advanced flue gas cleaning technologies plays a significant role in expanding the utilization of coal in the commercial and industrial market. Advanced combustor concepts currentiy being developed for the commercial and industrial inarkets will burn cleaned, ultra-fine coals, but will also need flue gas cleaning in order to control emission of $\mathrm{SO}_{\mathrm{x}}, \mathrm{NO}_{\mathrm{x}}$ and particulates. Control of emissions of fine particulates is particularly important for this class of combustors, given the very fine coal particles being burned. The proposed particulate cleanup device, the Contined Vortex Scrubber (CVS), has several novel features, and is described below.

The CVS, which is 11lustrated in Figure 2-1, consists of a cylindrical vortex chamber with tangential flue gas inlets. The clean gas exit is via a tangent slot in a central tube. Liquid is introduced into the chamber and is confined within the vortex chamber by the centrifugal force generated by the gas flow itself. This confined liquid forms a layer through which the flue gas is 

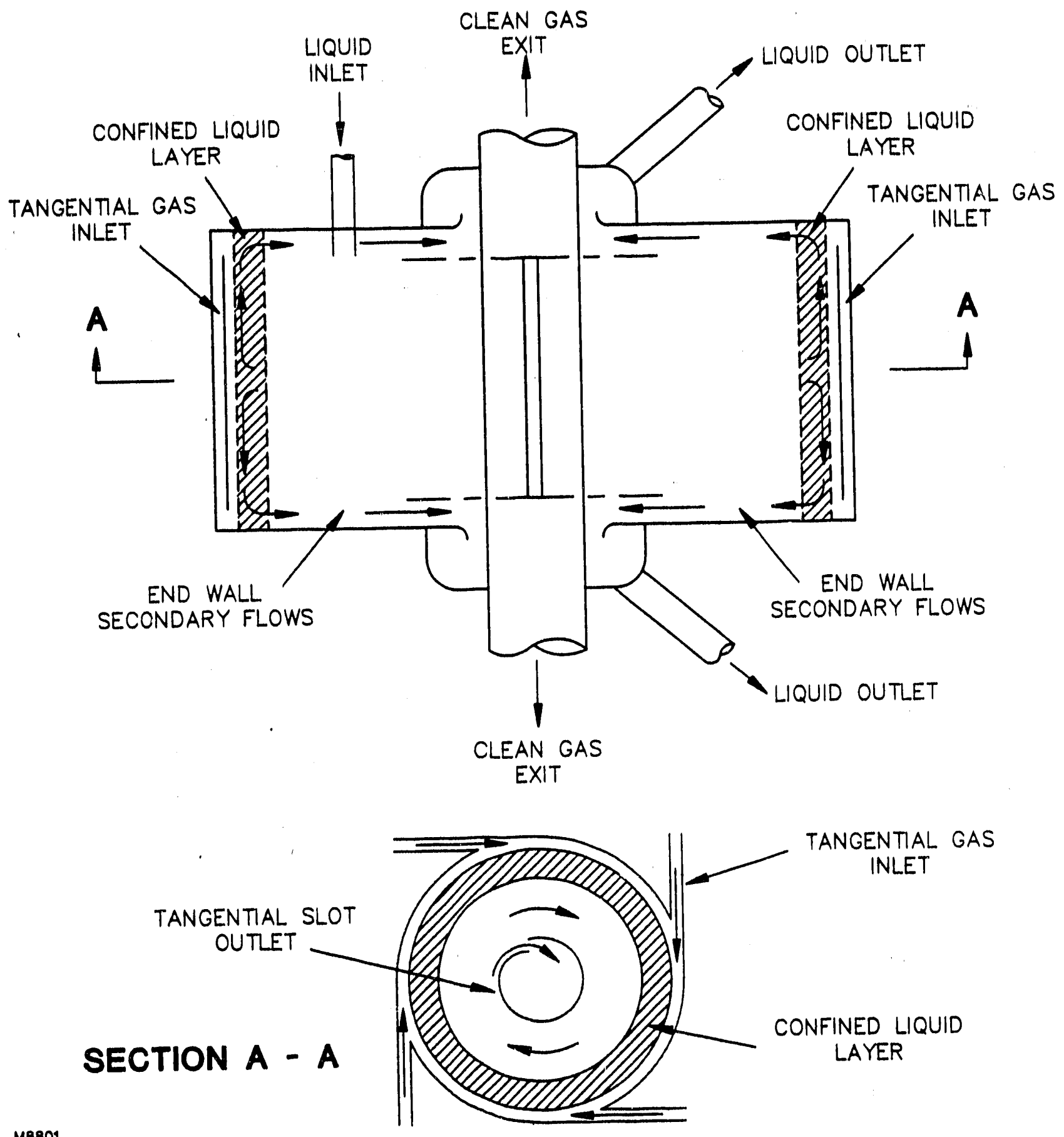

M8801

Figure 2-1 Schematic Diagram of Confined Vortex Scrubber 
then forced to bubble, producing a strong gas/liquid interaction, high inertial separation forces and efficient particulate cleanup. In effect, each of the suli-millimeter diameter gas bubbles in the liquid layer acts as a micro-cyclone, inertially separating particles into the surrounding liquid.

The establishment of a simple, steady flow field, with maximum radial acceleration and low pressure drop is of key importance in obtaining good separation performance. The vortex chamber geometry is chosen to allow such a flow field. The end wall secondary flows which occur in all cyclonic type flows are explicitly used as a removal path for water laden with solids inertially separated from the bulk flow. This water is cleaned using conventional fiber filter technology and then recycled to the vortex chamber.

The combination of design features described above is projected to lead to very high separation efficiencies for fine particulates, while maintaining a simple, compact geometry. The CVS retains the inherent mechanical simplicity of cyclonic-type separators. The lack of moving parts should lead to reliable, low maintenance operation. The CVS also has the potential for enhancing SO, removal from coal combustor product streams. This could be accomplished by suitable choice of the liquid scrubbing medium.

\subsection{DESCRIPTION OF APPROACH}

The overall objective of the program is to develop an efficient fine particle removal technology based on a confined vortex scrubber particulate control device applicable to small scale coal combustors. In order to meet this objective, an experimental program supported by analytical efforts is underway. Specific objectives are to (1) verify the proposed particulate cleanup concept by laboratory experiments, (2) investigate and optimize performance by varying 
design and operating parameters in the experiments, (3) investigate the scaling of the proposed cleanup concept, and (4) demonstrate efficient removal of fine particulates to sufficiently low levels to meet proposed small scale combustor emission standards.

The experimental tests are divided into two main areas: (1) investigation of the single and two-phase vortex flow field in the CVS and (2) investigation of the cleanup performance of the CVS. The experiments are being conducted at a scale and in a method appropriate for proof of concept. The analytical efforts is mainly related to the correlation of experimental data and to the questions of scaling of the device to larger sizes.

An schedule chart for the program with milestones marked is presented in Figure 2-2. The program will last 12 months. The scope of the work is broken into tasks as follows:

Task 1: Project Work Plan

Task 2: Design Experiment

Task 3: Fabricate Experiment

Task 4: Vortex Flow Experiments

Task 5: Cleanup Experiments

Task 6: Data Analysis

Task 7: Reporting and Management

The emphasis in all the experiments is on development of an optimized CVS configuration. The schedule is thus designed to accommodate feedback between design and experiment. Accordingly, the CVS design work (Task 2: Design Experiment) and fabrication work (Task 3: Fabricate Experiment) overlaps with the early part of CVS testing (Task 4: Vortex Flow Experiments): this to allow 


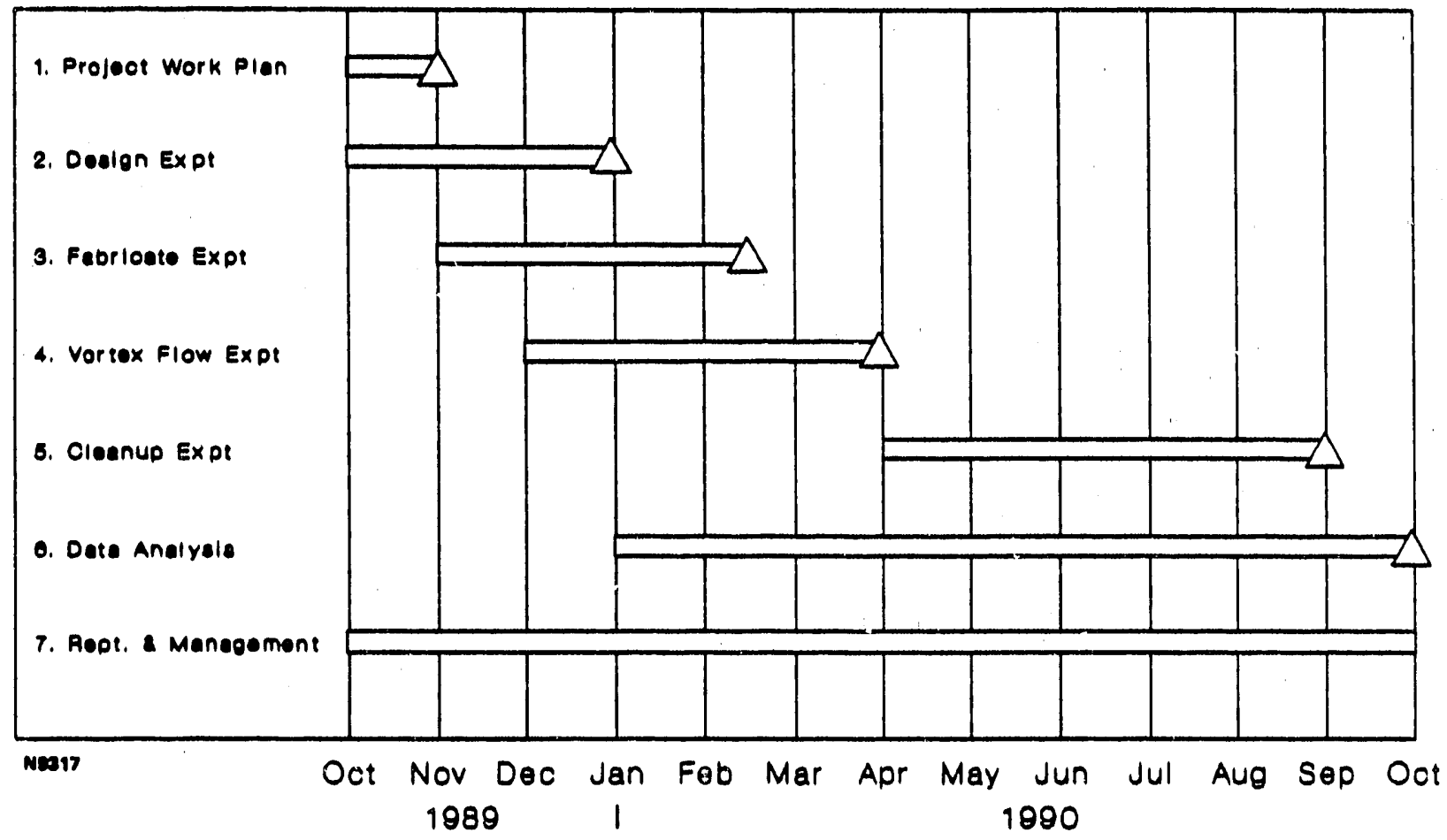

Figure 2-2 CVS Program Schedule 



\subsection{TECHNICAL PROGRESS}

\subsection{TASK 2: DESIGN EXPERIMENT}

\subsubsection{CVS Desian Concept}

In the late 1960s and early 1970s, the confinement of both liquids and solid particles in vortices was studied for application in nuclear rocket propulsion (Stickler et al., 1974, Lewellen and Stickler, 1972). In the early 1980s, Avco Research Laboratory performed experiments, under IR\&D funding, directed towards development of a hot gas cleaning system based upon a similar concept (Avco Research Laboratory, 1982). The results of these two studies provide a theoretical and experimental base for the proposed flue gas cleaning device. Both of these experiments were performed at atmospheric pressure using essentially similar geometries. In developing the design of the CVS, the geometries and configurations of these earlier devices were studied.

Key to the separation performance of the CVS is the establishment of a stable vortex flow with strong radial acceleration. The geometry of the CVS has been chosen with this aim in mind. The gas is injected into the chamber tangentialiy, and after passing through the confined liquid layer, exits through tangent slots in a central cylindrical tube, see Section A-A, Figure 2-1. The vortical flow field produced is thus much simpler and more stable than that produced in a conventional cyclone separator. In a conventional cyclone, the downward-spiralling flow is forced to reverse direction in order to spiral back up the center of the tube and reach the exit: this reversal of axial flow direction represents a fundamental source of instability. Though a detailed understanding of the complex flow in a reverse flow cyclone separator is lacking, a number of the salient features which lead to its performance 
weaknesses have been known for a long time. Visualization of cyclone separator flows (Smith, 1962) reveals the sudden and unpredictable onset of periodicity in the flow. This was associated with the precessing of the vortex attachment point on the cyclone barrel wall. The CVS geometry eliminates the possibility of this type of instability. Smith also describes a mechanism for the re-mixing of separated particles in a conventional cyclone, which occurs because of the instability of the outer wall boundary layer to radially inward displacement. Due to the deceleration of the fluid by viscous forces, the thickness of the wall boundary layer grows. The breaking away of parts of this thickened, lowmomentum fluid layer and its radialiy inward flow are the sources of the high curbulence in the cyclone separator and are responsible for the remixing of previously separated particles.

A number of studies have been made of the performance of modified cyclone geometries (Yellott and Broadley, 1955, Smith, 1962, Schmidt, 1986) in order to address this problem. General Electric (1980) identified the principal cause of poor cyclone performance as "short-circuiting", i.e. the direct passage to the exit duct of a portion of the inlet flow. Design modifications made as a result of recognizing this mechanism led to significant improvement in performance of a development cyclone.

A more recent paper (Schmidt, 1986) addresses the same problem in a different way. The conventional cyclone vortex finder exit tube was replaced by a pipe with a closed bottom end and a twisted entrance slot with a diffuser channel around the periphery. The objective was to provide a linearly distributed sink in the cyclone barrel, as opposed to the strong local sink provided by a conventional cyclone exit. The addition of the outlet tube halved the cyclone pressure drop and significantly improved the grade efficiency, the 
99\% cut diameter being reduced from 9 microns to 3.3 microns. Further investigation of the cyclone flow field determined that a significant part of the performance improvement could be attributed to the elimination of large radially inward velocities in the vicinity of the exit pipe opening.

Unlike the geometries investigated in the MIT liquid containment studies and the ARL IR\&D work described above, the proposed exit geometry for the coni ined vortex scrubber, Figure 2-1, provides a uniformly distributet sink outlet along the whole length of the vortex chamber. This has two advartages: firstly, the need for the flow to reverse direction in order to exit the chamber is removed, leading to a more stable flow field; secondly, this choice of exit geometry allows the use of both end wall secondary flows as dust removal paths. The considerably reduced pressure drop obtained with this kind of outlet is expected to be preserved.

The end wall secondary flows which occur in all cyclonic type flows are explicitly used as a removal path for water laden with solids inertially separated from the bulk flow. Having utilized the end wall secondary flows as the dust removal mechanism, there exists the possibility of controlling these flows by selectively altering the exit back pressures in the clean and dirty gas outlets. The geometry of the CVS therefore provides a much greater degree of control over the flow field than does that of a conventional cyclone. Thus the separation performance of the device may be optimized for a given set of operating conditions.

\subsubsection{CVS Desian Details}

The initial CVS configuration was designed and fabricated to provide as much flexibility as possible in testing. A modular design was adopted, in order to allow rapid variation of CVS geometry. 


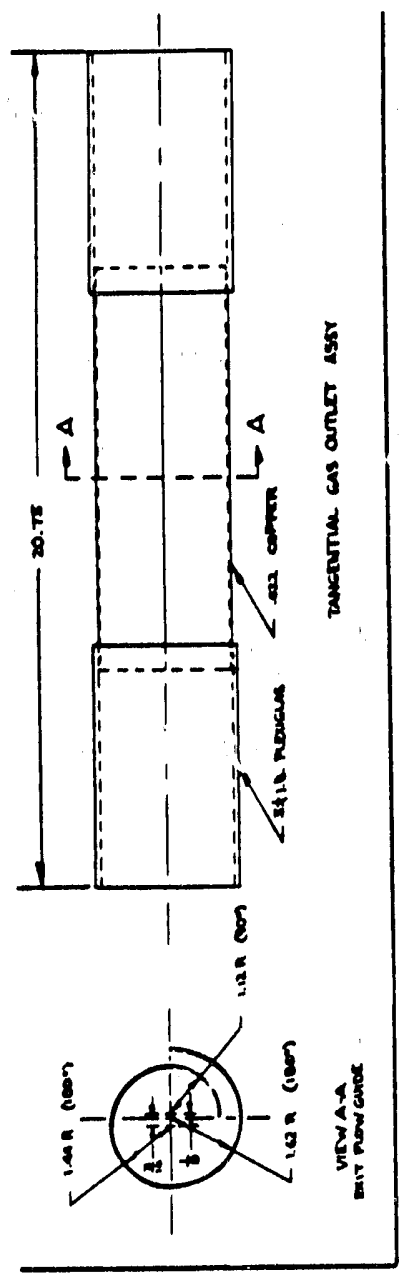

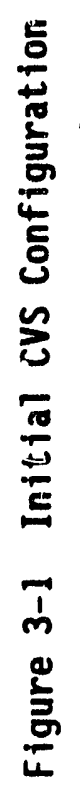
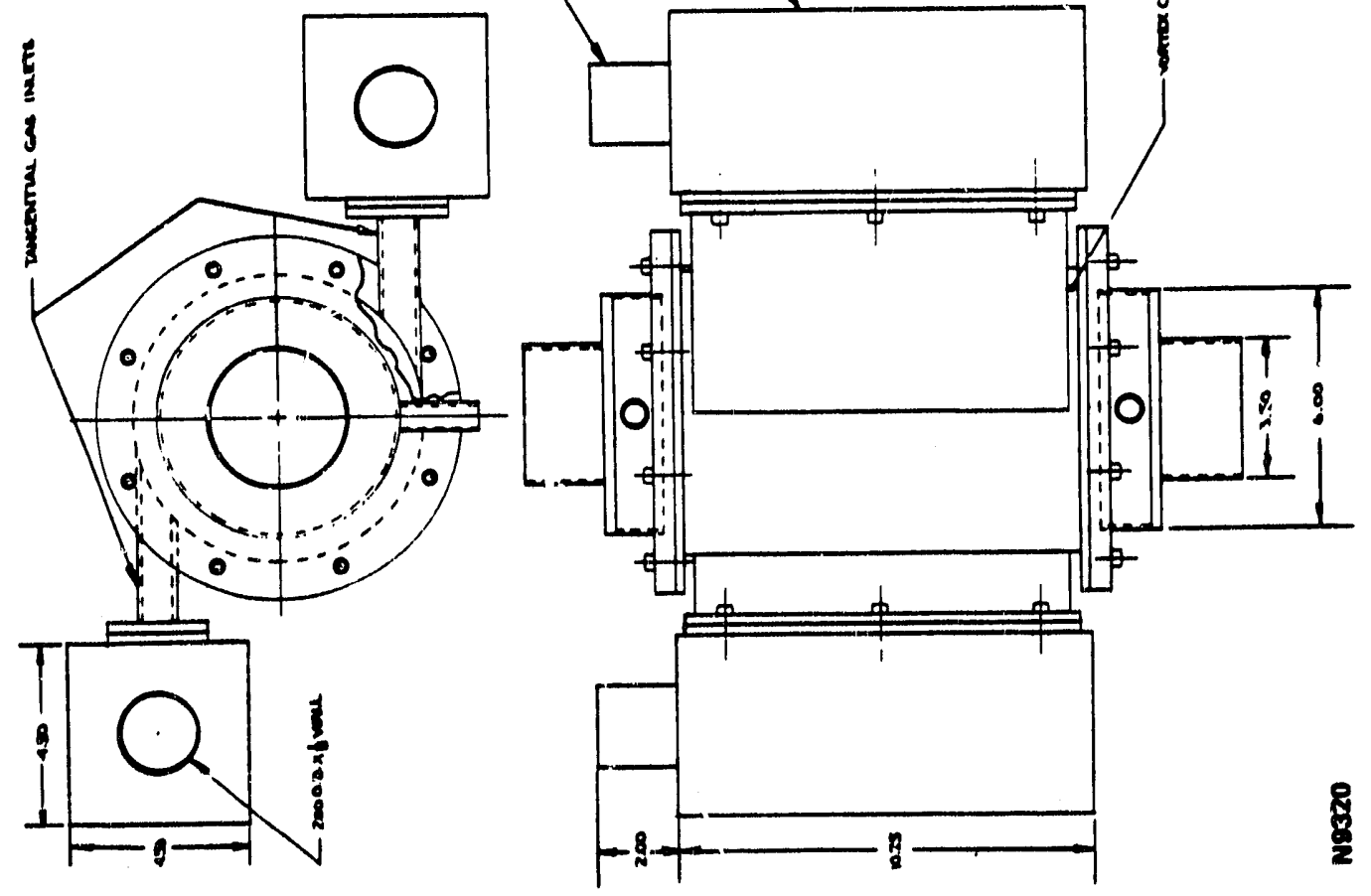
Chamber Dimensions. The design developed is illustrated in Figure $3-1$ and the main design parameters and their parametric variations are listed in Table 3-1. The firsi design parameter to be established was the chamber diameter. This was established by considering the nominal design mass flow. The CVS was designed for a nominal mass flow equivalent to that of the exhaust gas from a

TABLE 3-1

CVS GEOMETRY AND PARAMETRIC VARIATIONS

Parameter

Chamber Internal Diameter Aspect Ratio (L/D)

Air Inlet Type

Air Outlet Type

Air Outlet Diameter $\left(D_{0} / D\right)$

Water Outlet Type

\section{Design Value}

$6.5^{\prime \prime}$

1.5

Slots

Slot

0.50

Single Tube
Parametric Variation

1.0

Jets

Vortex Finder

0.25

Multiple Tubes

$1 \mathrm{MM} \mathrm{Btu} / \mathrm{hr}$ coal combustor. This is approximately $0.22 \mathrm{lb} / \mathrm{s}$. The MIT chamber was run at mass flows of up to $0.13 \mathrm{lb} / \mathrm{s}$ and the ARL IR\&D experiment was run at mass flows up to $1.1 \mathrm{lb} / \mathrm{s}$. Thus in terms of size and flow rate the cVs falls between these two previous experiments. The diameters of the MIT and ARL IR\&D chambers were $4 \mathrm{in}$. and $11 \mathrm{in}$. respectively. The CVS chamber internal diameter was fixed at $6.5 \mathrm{in}$. This is appropriate from a mass flow scaling point of view and also means that readily available plexiglas tube material can be used for construction.

Aspect ratios (chamber length/diameter) in the range 1.0 to 1.5 are of interest. From a construction standpoint, it was simpler and more cost effective to manufacture two chambers of different lengths rather than one chamber of variable length. Chambers of aspect ratio 1.0 and 1.5 were 
constructed.

Air Inlet Geometry. The nominal air inlet geometry chosen was two diametrically opposite tangential slots. The air inlet slot geometry was designed to accept inserts of differing thicknesses, see Figure 3-2, in order to allow separate control of mass flow and inlet velocity in the experiments. Two inserts were manufactured to give three possible slot heights. The minimum slot height was chosen to give approximately $120 \mathrm{ft} / \mathrm{s}$ tangential inlet velocity at the design mass flow rate. In addition, a jet insert was also designed. This insert, see Figure 3-2, allows a change of air inlet geometry from tangential slots to rows of tangential jets.

Air Outlet Geometry. The nominal design air outlet geometry is based on the Schmidt flow guide described above, but instead of having a twisted slot, a straight slot is provided. At either end, the slotted tube is connected to an open ended lube which passes through the water out-take chamber to the air exit duct, see figure 3-3. Two slotted exit tubes were designed, one having a diameter of half the chamber internal diameter and one of one quarter the chamber internal diameter. In addition, conventional vortex finder air exits were provided: these are simply open ended tubes which protrude into the vortex chamber at either end, see Figure 3-3.

Water Inlet. The initial water inlet arrangement consists simply of two small stainless steel tubes, 0.125 in. ID, which protrude axially into the main chamber close to the walls, see Figure 3-4. The ends of the tubes are sealed and the water enters the chamber through a series of holes. Thus the water is sprayed into the chamber in the same direction as the tangential air intet flow.

Water Outlet. The initial water outlet arrangement is shown in Figure 34. The water 1eaves the main chamber in the end wall secondary flows and passes 

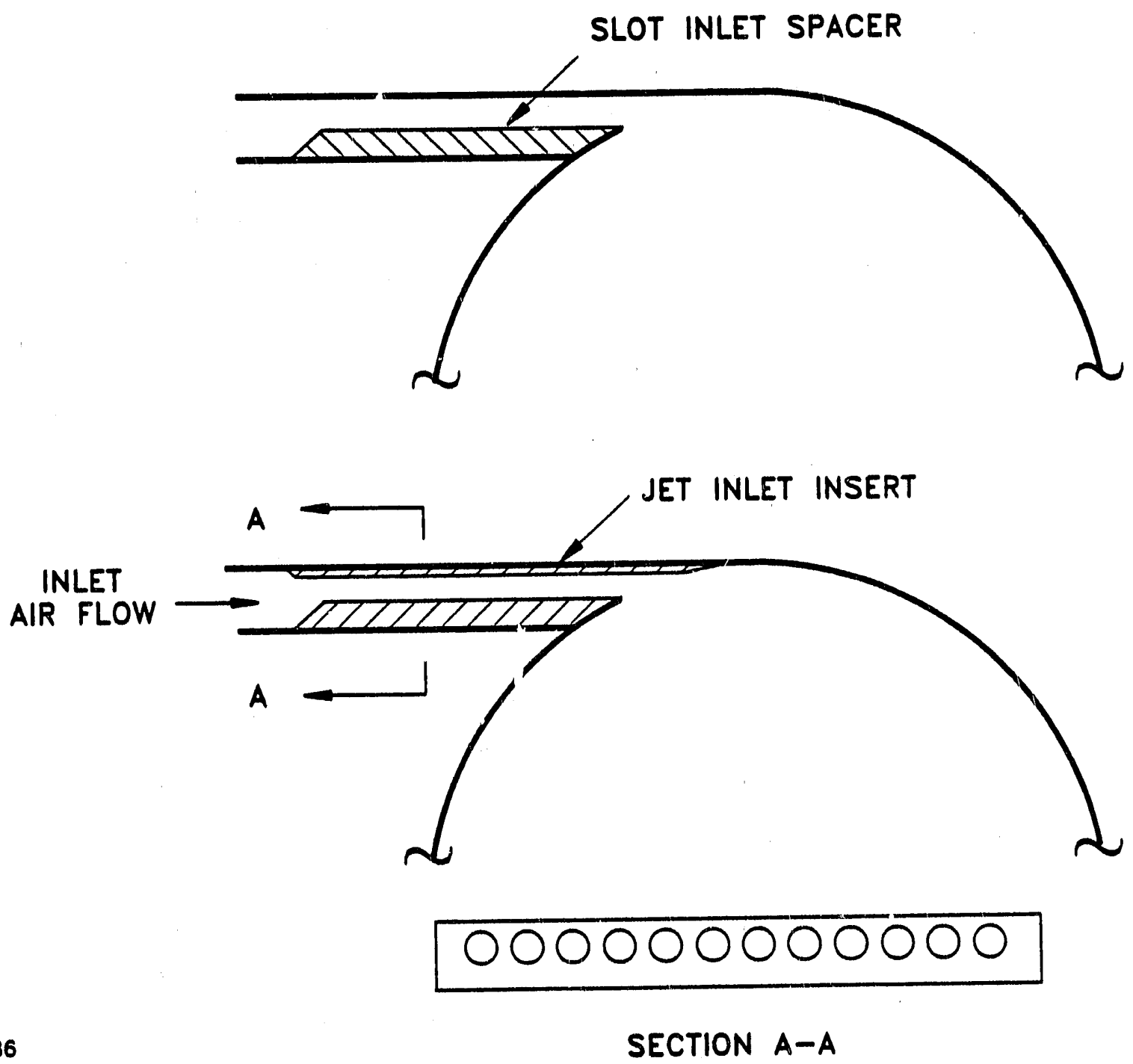

Figure 3-2 CVS Air Inlet Geometries 

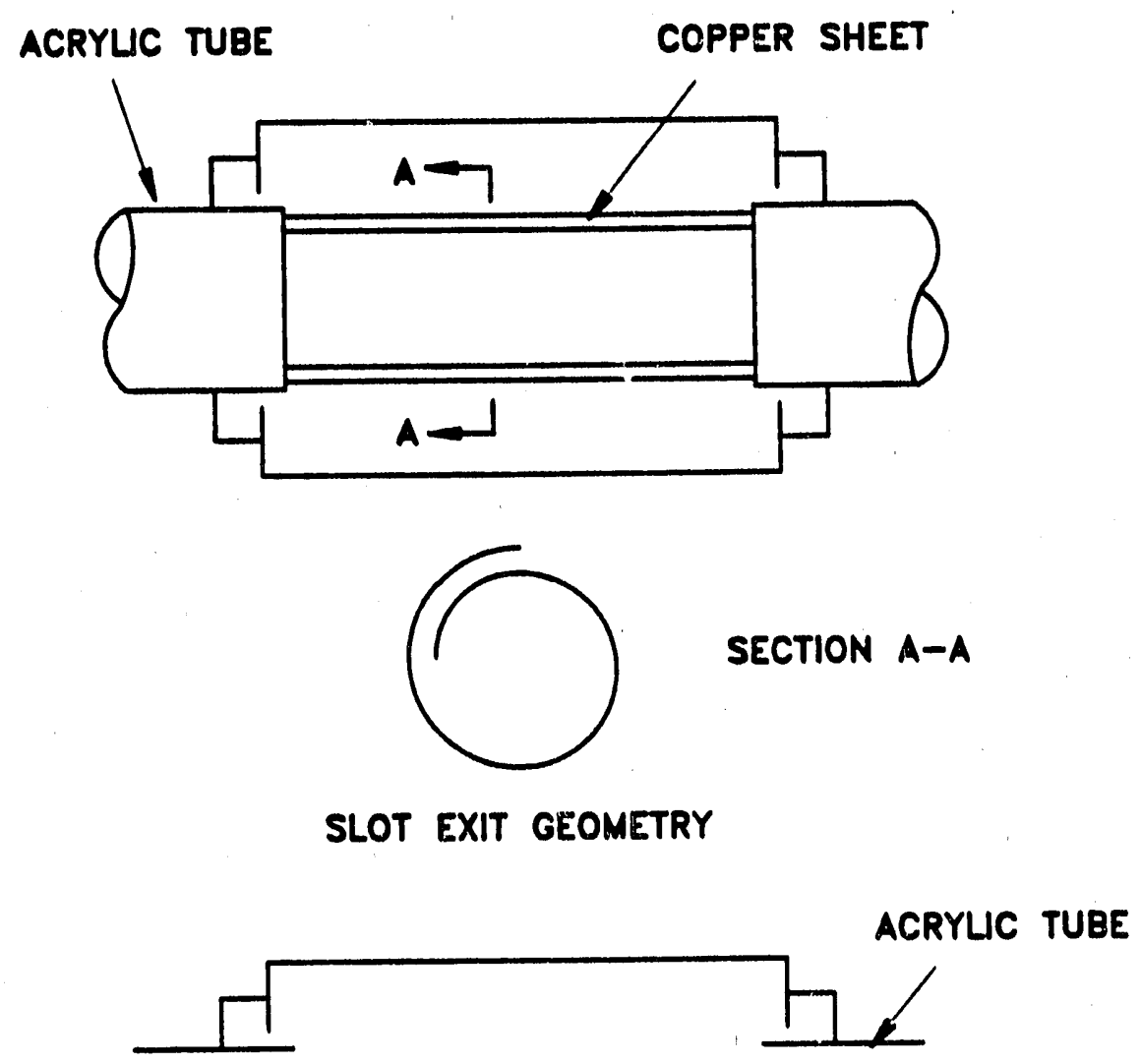

P1009

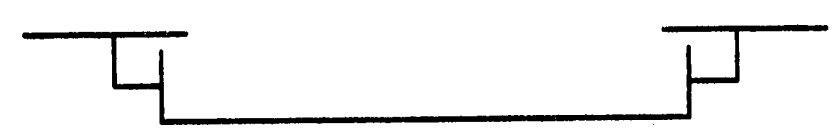

VORTEX FINDER EXIT GEOMETRY

Figure 3-3 CVS Air Outlet Geometries 
through an annulus into the water out-take chamber. A 0.372 in. ID water outlet tube located at the bottom of this chamber allows the water to leave the CVS entirely.

Porous Walls. Porous chamber walls were considered at the outset of the Jesign effort, for the following reasons. In the MIT liquid containment studies, gas was introduced into the vortex chamber through six tangential ports and also through a porous cylindrical sidewall. The radial flow through the sidewall provided transpiration cooling of that wall, an important requirement to the application then being considered. In addition, however, it was noted that the radial inflow provided a beneficial effect on both pressure drop and liquid containment. In the CVS the inlet flow contains fine fly ash particles, so inclusion of a porous wall poses a variety of problems, not least of which is the potential for complete plugging of the pores with fly ash. Given the anticipated pressure drop benefits of the CVS outlet geometry and in the interests of simplicity, it was decided to avoid the added complexity of a porous chamber wall.

\subsubsection{Experimental Arrangement}

The experimental arrangement is illustrated schematically in Figure 3-5. The test gas is supplied by a regenerative blower (Rotron Model DR-P7). This blower is capable of supplying some $200 \mathrm{scfm}$ at 90 inches water column ("W.C.) and approximately twice this airflow at 40" W.C. A butterfly valve in the air supply by-pass line allows control of the mass flow of test gas to the CVS. The by-pass air is exhausted outside the building. The test gas is fed to the CVS via a sharp-edged orifice plate, for mass flow measurement, and two inlet manifolds. The manifolds connect directly to the CVS slot inlets. The two exhaust air streams from the CVS are merged before being exhausted outside the 

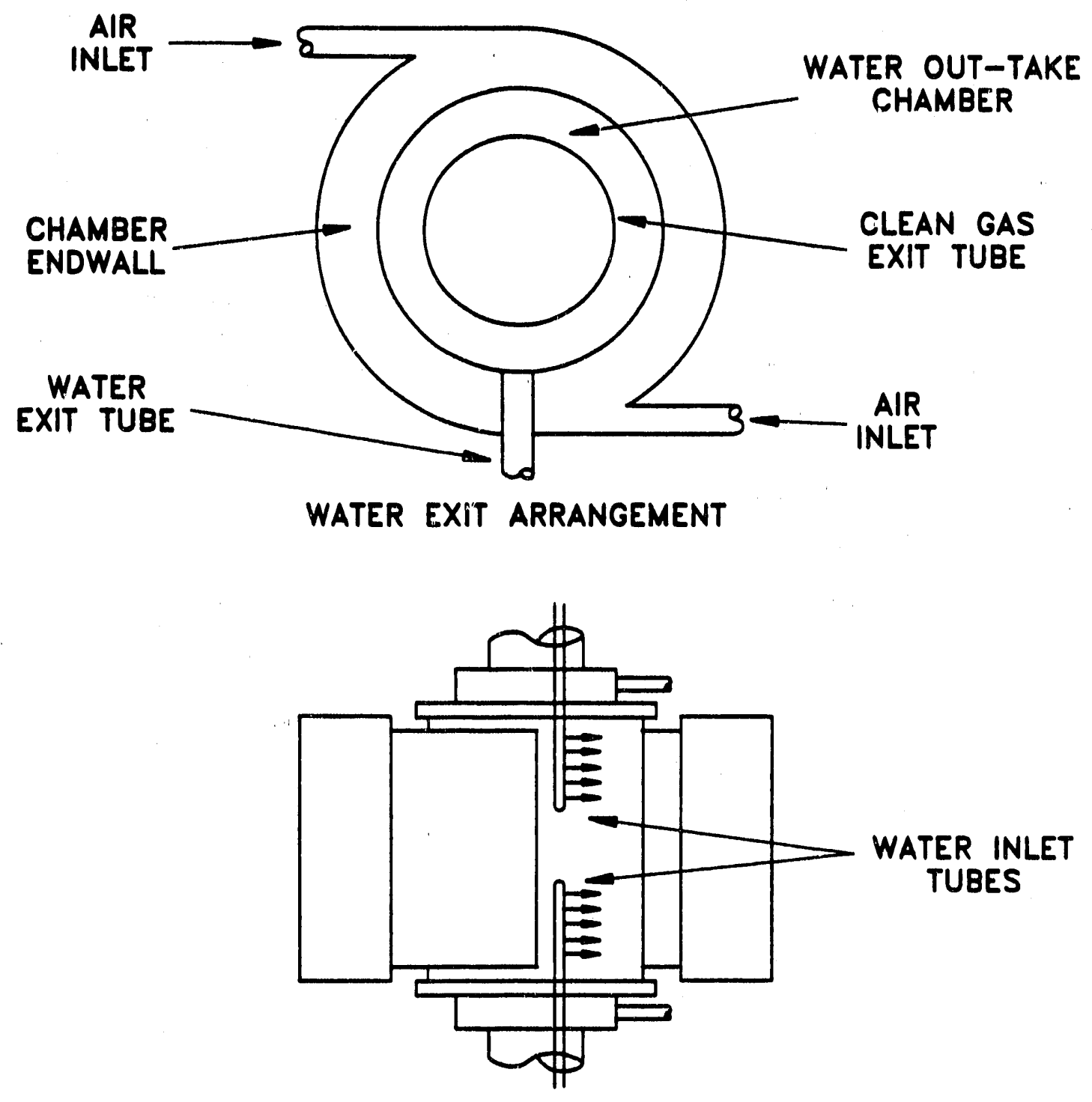

P1990

WATER INLET ARRANGEMENT

Figure 3-4 CVS Water Inlet and Outlet Arrangements 


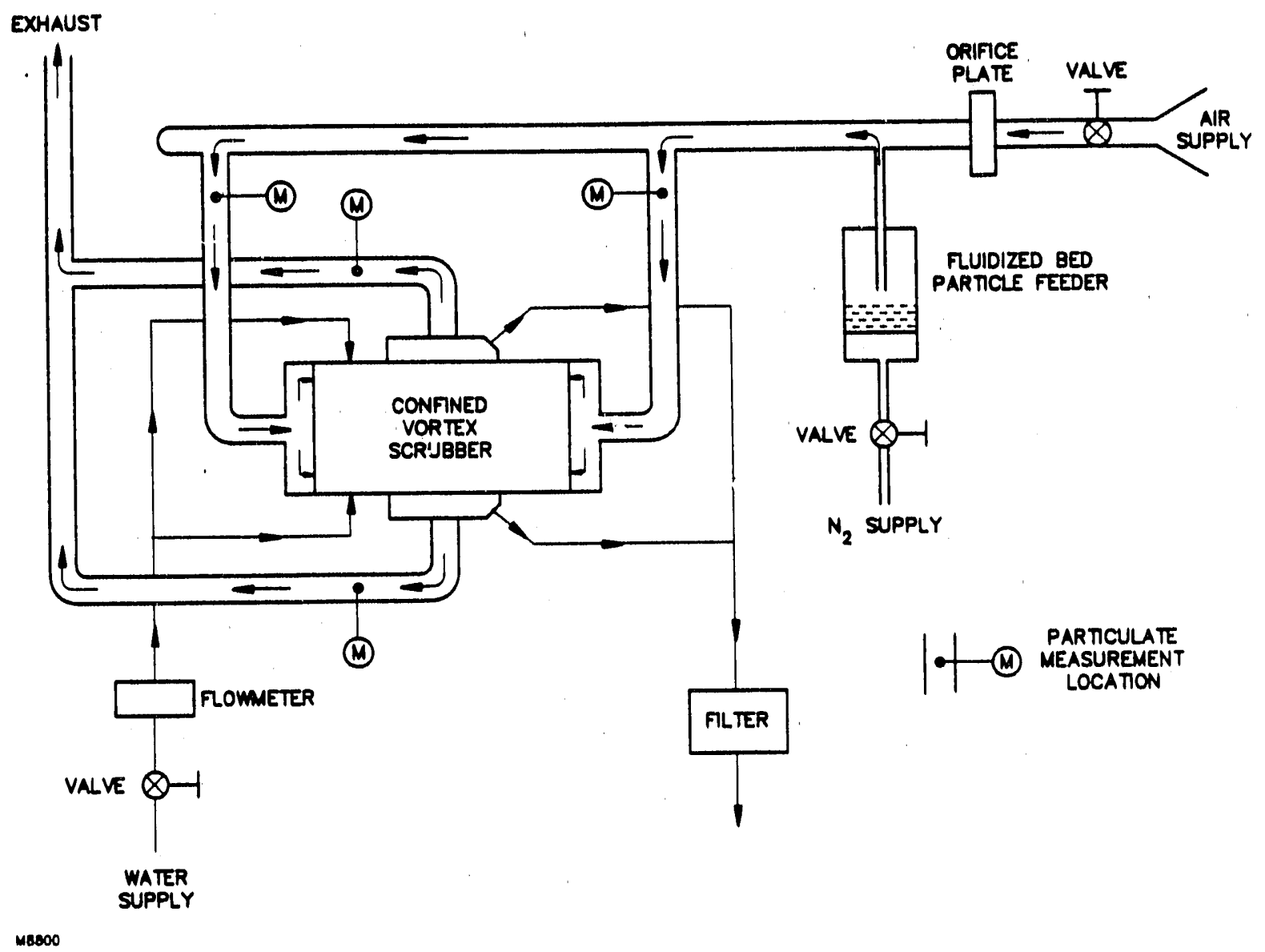

Figure 3-5 CVS Experimental Arrangement 
building. Standard pressure and temperature instrumentation is used. A photograph of the experimental installation is shown in Figure 3-6.

\subsection{TASK 3: FABRICATE EXPERIMENT}

Fabrication of all CVS hardware was carried out at ARL. The CVS chamber, end-walls, air inlet arrangement and water out-take chamber were fabricated frcm transparent acrylic (Plexiglas). This was to aid visualization of the interna: flow field. The sict exits were fabricated from copper sheet, which was formed to the correct contour. The copper sheet was then attached to an acrylic tube at either end.

The air inlet and outlet piping system was fabricated from Schedule 40 PVC piping and fittings. Flexible PVC hoses were used to connect the inlet manifolds and the outlet tubes to the PVC supply and exhaust pipes. Tygon tubing was used to connect the water supply and exhaust. The experiment was assembled in Test Cell \#2 at ARL's Haverhill, Massachusetts test facility.

No significant problems were encountered in fabricating and installing the CVS experiment as designed, though small changes in dimensions and geometry were necessary in order to simplify machining and assembly. A small delay in fabrication was incurred due to a temporary manpower shortage at ARL Haverhill. Installation of the experiment was completed in the third week of December, 1989.

\subsection{TASK 4: VORTEX FLOW EXPERIMENTS}

As discussed in Section 1, above, the emphasis here is on experimental development of an optimized CVS configuration. The target in the Vortex flow Experiments is to develop a CVS configuration with a stable flow field, high 


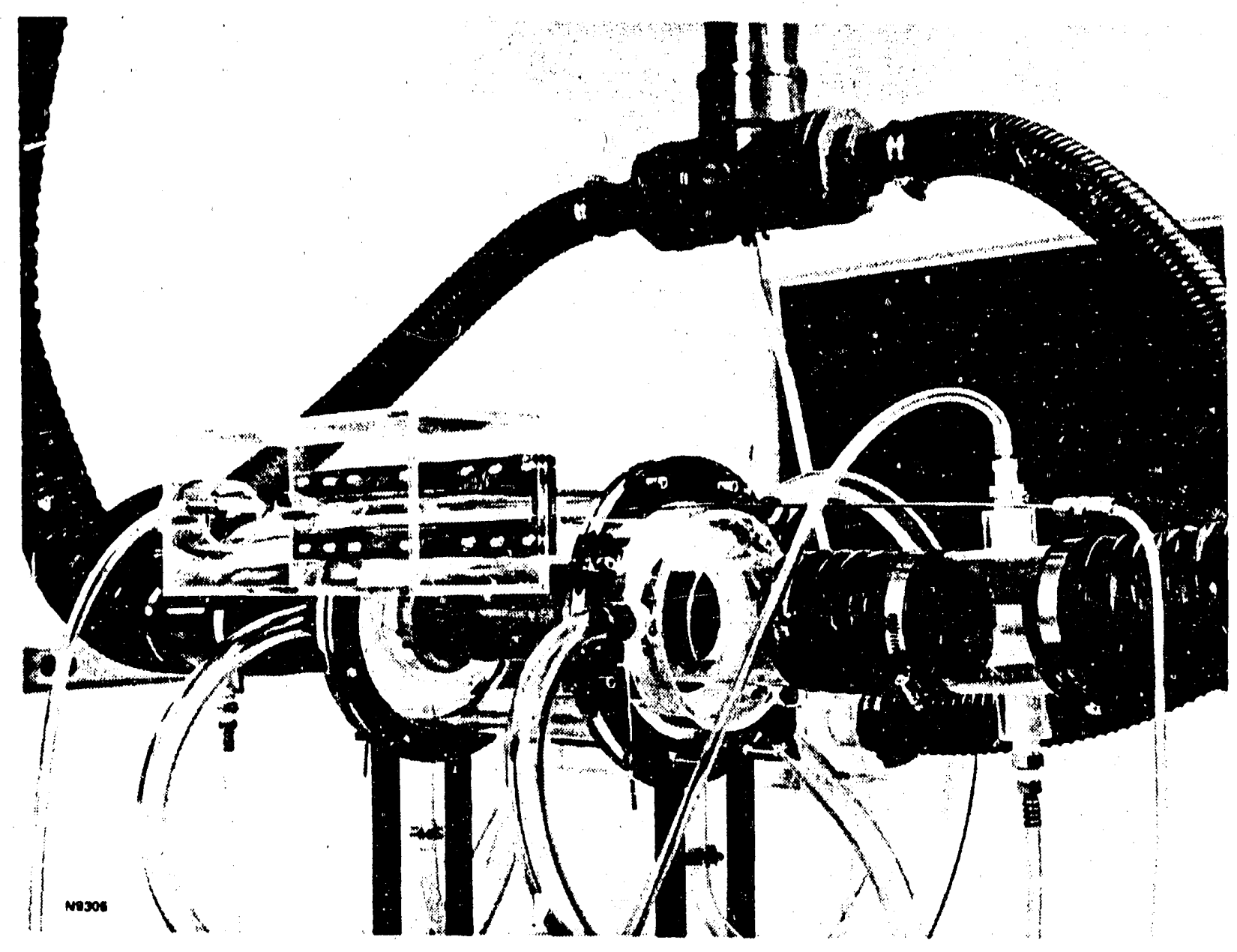

Figure 3-6 Photograph of Experimental Installation at ARL Haverhill 
radial acceleration, good liquid confinement and an acceptable pressure drop. These goals are summarized in Table 3-2. Technical issues of interest in these experiments include the degree of radial acceleration possible, the pressure drop, the degree of liquid containment, the stability of the two phase flow field, the water loss rate, the pressure drop and the control of the dirty water exit flow using the end wall secondary flows.

\subsubsection{Shakedown Experiments}

Shakedown experiments proceeded smoothly and took only a few days to complete. At the start of testing, a shell and tube heat exchanger was installed in the CVS air supply system, between the blower and the CVS. This was done to prevent the possibility of over-heating the acrylic components of the CVS. Acrylic is only rated to $140^{\circ} \mathrm{F}$, and the blower air can reach temperatures greater than $150^{\circ} \mathrm{F}$ when operated at high pressure rise ( 80 - $90^{\prime \prime}$ W.C.) arid low mass flow.

Overall air flow characteristics, mass flow rates and system pressure drops and operating temperatures were evaluated. Initial observations were that the blower was operating at close to maximum pressure rise and minimum flow rate, but that the bulk of the system pressure drop was across the heat exchanger itself. The maximum mass flow rate which could be obtained through the CVS was only approximately 85 percent of design mass flow. At this maximum mass flow rate the tangential inlet velocity was $40 \mathrm{ft} / \mathrm{s}$. Without the heat exchanger operating, the temperature of the test gas at the orifice plate reached $130^{\circ} \mathrm{F}$ after the blower had been operating for 12 minutes.

The heat exchanger was removed and another test was run. The system pressure drop was much lower, consequently the blower operated at a lower outlet temperature. The air temperature at the orifice plate stabilized at 
TABLE 3-2

PF.RFORMANCE OBJECTIVES FOR VORTEX FLOW EXPERIMENTS

Pressure drop

Mass of liquid contained in chamber

Controllable end wall outlet flows

Stable two phase flow field
Comparable to conventional cyclone separator (approximately $10-12$ inlet idynamic heads)

Equivalent to approximately $10 \%$ of chamber volume

TABLE 3-3

CVS CONFIGURATIONS FOR AERODYNAMIC TESTS

\begin{tabular}{|c|c|c|c|c|c|}
\hline Configuration & $L / D$ & D.LD & $\underline{S / D}$ & Air Exit & Water Exit \\
\hline $\begin{array}{l}A \\
B \\
C \\
D \\
E \\
F\end{array}$ & $\begin{array}{l}1.50 \\
1.50 \\
1.50 \\
1.50 \\
1.50 \\
1.50\end{array}$ & $\begin{array}{l}0.25 \\
0.25 \\
0.50 \\
0.50 \\
0.50 \\
0.50\end{array}$ & $\begin{array}{l}0.077 \\
0.077 \\
0.077 \\
0.045 \\
0.045 \\
0.035\end{array}$ & $\begin{array}{l}S \\
V \\
S \\
S \\
S \\
S\end{array}$ & $\begin{array}{l}W 1 \\
W 1 \\
W 1 \\
W 1 \\
W 2 \\
W 2\end{array}$ \\
\hline
\end{tabular}

Legend

$L=$ Chamber Length

$D=$ Chamber Diameter

$D_{1}=$ Exit Tube Diameter

$S=$ Inlet Slot Height

Air Exit: $\quad S=$ Slot Exit

$V=$ Vortex Finder Exit

Water Exit: $\quad W 1=$ One $0.372 "$ ID Exit Tube

W2 = One 0.372" Exit Tube + Three 0.627" Exit Tubes 
approximately $120^{\circ} \mathrm{F}$. With the heat exchanger removed the design mass flow rate through the cVS could easily be achieved.

\subsubsection{Aerodynamic Tests}

Initial tests were made without water addition and were primarily concerned with flow field stability and device pressure drop. The CVS configurations tested are specified in Table 3-3. In all aerodynamic tests to date, the aspect ratio (chamber length/diameter) was fixed at 1.50. Two slot exit tube diameters, two air exic types (slot and vortex finder) and two water exit arrangements (single and multiple tubes) were tested.

Measured pressure drop results for the six configurations detailed in Table 3-3 are presented in Figure 3-7. Pressure drop is expressed as a percentage of the chamber inlet total pressure and is shown as a function of the chamber tangential inlet velocity. Configurations $A$ and $B$ (small exit diameter) demonstrated high pressure drops. These tests were performed with the heat exchanger installed, consequently the system mass flow, and hence inlet velocity, was limited. Nonetheless, the dramatic increase in pressure drop produced by changing from the slot exit (Configuration $A$ ) to the vortex finder exit (Configuration $B$ ) is evident. At the same inlet mass flow and velocity, the vortex finder exit produced a 50 percent higher pressure drop than the slot exit.

The effect of exit diameter may be seen by comparing Configuration $A$ and Configuration $C$. At the same inlet velocity and mass flow, the smaller exit tube gives approximately three times the pressure drop of the larger exit tube. Reduction of the inlet slot height allowed higher inlet velocities and hence the production of greater radial accelerations. For the final configuration $(F)$, the slot height is $0.208 "$. This gives inlet velocities of up to $150 \mathrm{ft} / \mathrm{s}$. 


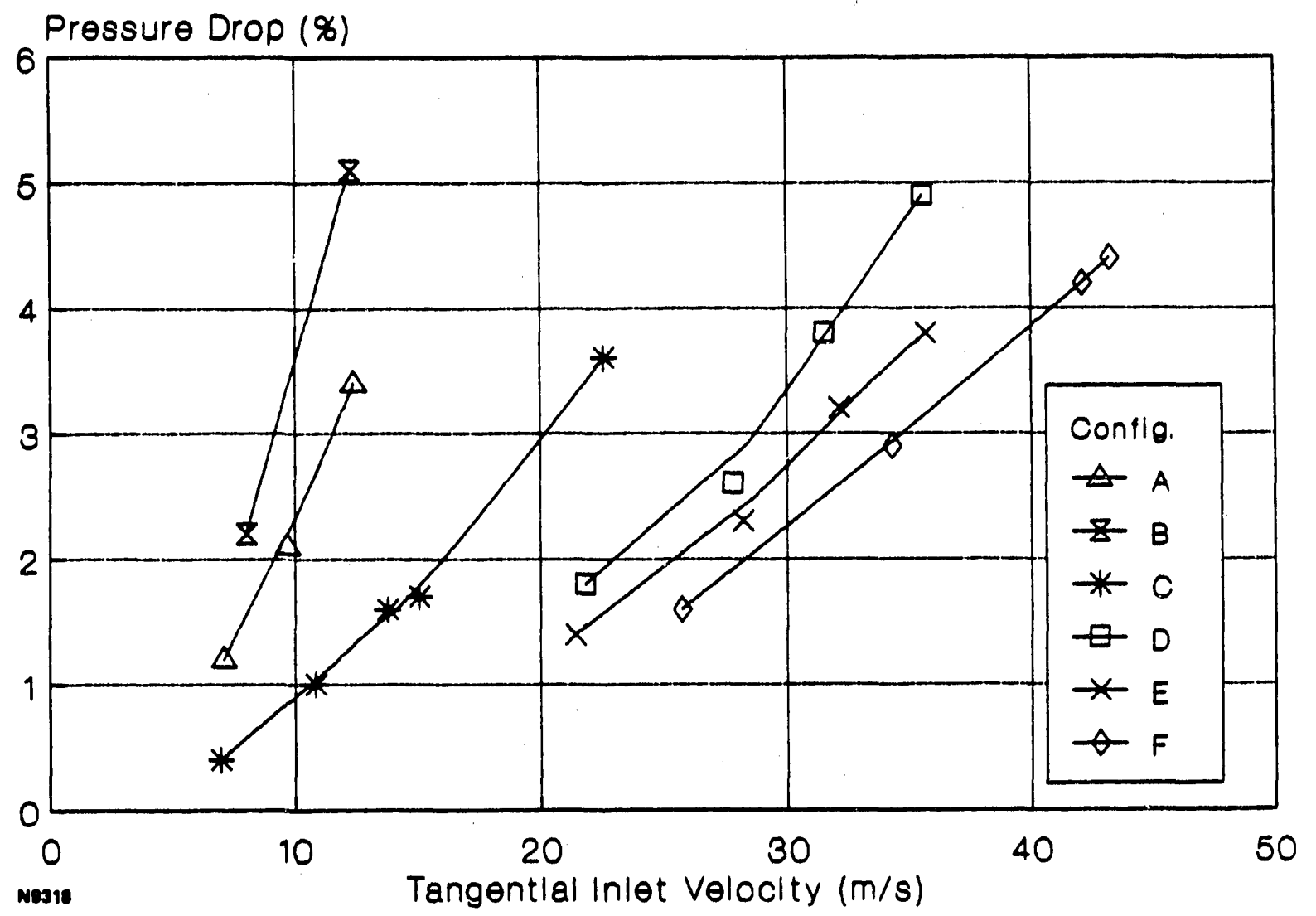

Figure 3-7 Measured Pressure Drop Data for Single Phase Flow, CVS Configurations as in Table 3-3 
It is useful and conventional to express pressure drops for inertial separators in terms of the number of inlet dynamic heads. This allows direct comparisons to be made between devices of differing geometries and scales. For example, the pressure drop of a conventional reverse flow cyclone separator of "high efficiency" design is in the range $10-12$ inlet dynamic heads. The nondimensional pressure drop for the six configurations tested is shown in Table 3-4.

The initial CVS configuration with the small exit tube therefore has a non-

TABLE 3-4

CVS NON-DIMENSIONAL PRESSURE DROP - NO WATER ADDITION

Configuration Number of Dynamic Heads Loss

$\begin{array}{ll}A & 40.7 \\ B & 62.0 \\ C & 13.2 \\ D & 6.6 \\ E & 5.4 \\ F & 4.4\end{array}$

dimensional pressure drop some four times greater than that of a conventional cyclone. The final crs configuration has a non-dimensional pressure drop of less than half that of a conventional cyclone. Figure 3-8 shows the non-dimensional pressure drop for the last four configurations as a function of inlet velocity. It is interesting to note that as the inlet slot height is reduced, the nondimensional pressure drop of the device was reduced.

of prime concern from a practical point of view is the device pressure drop at the design mass flow rate. This is shown in Figure 3-9 as a function 


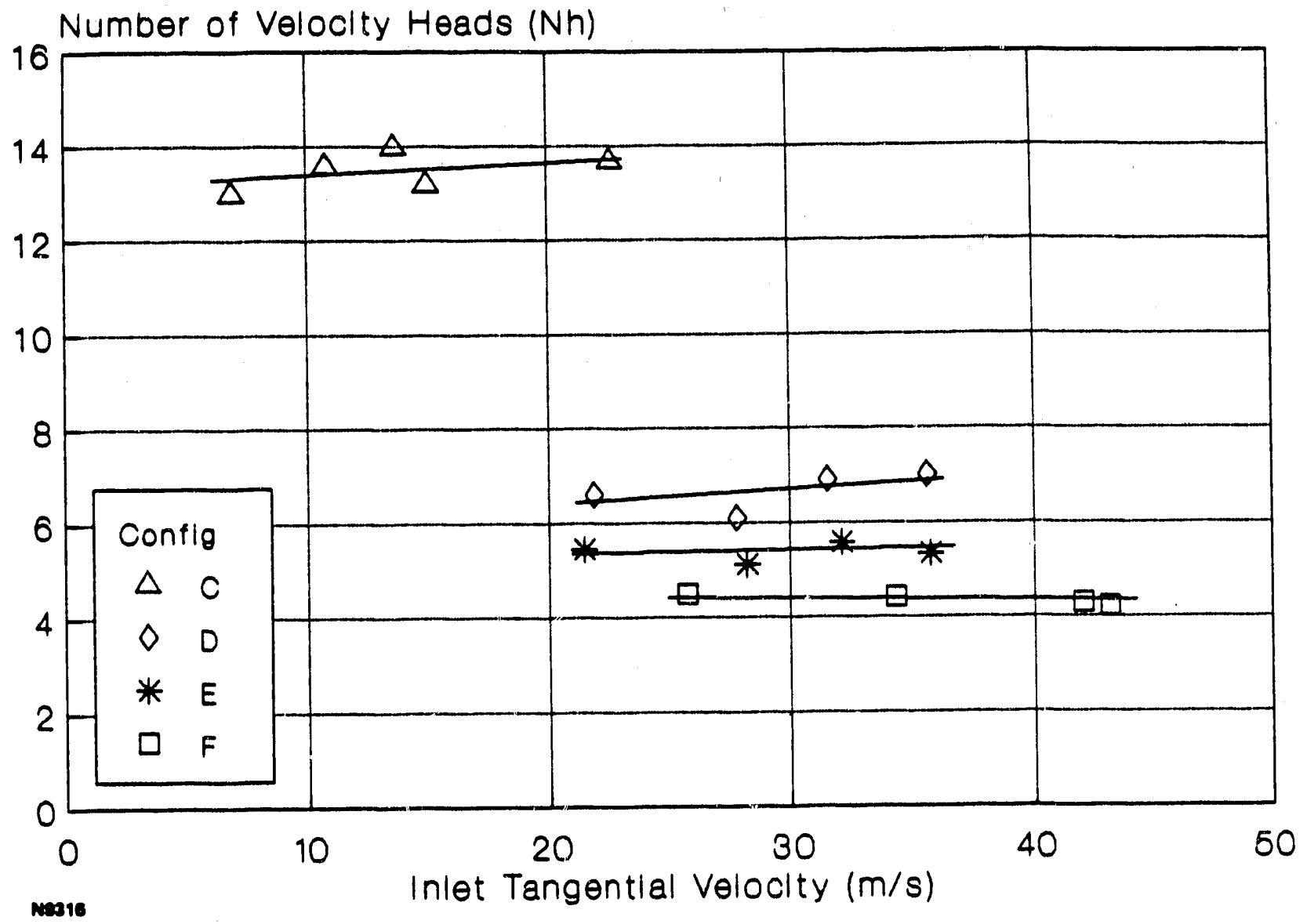

Figure 3-8 Meas:red Pressure Drop Expressed in Non-Dimensional Form, CVS Confijurations as Listed in Table 3-3 


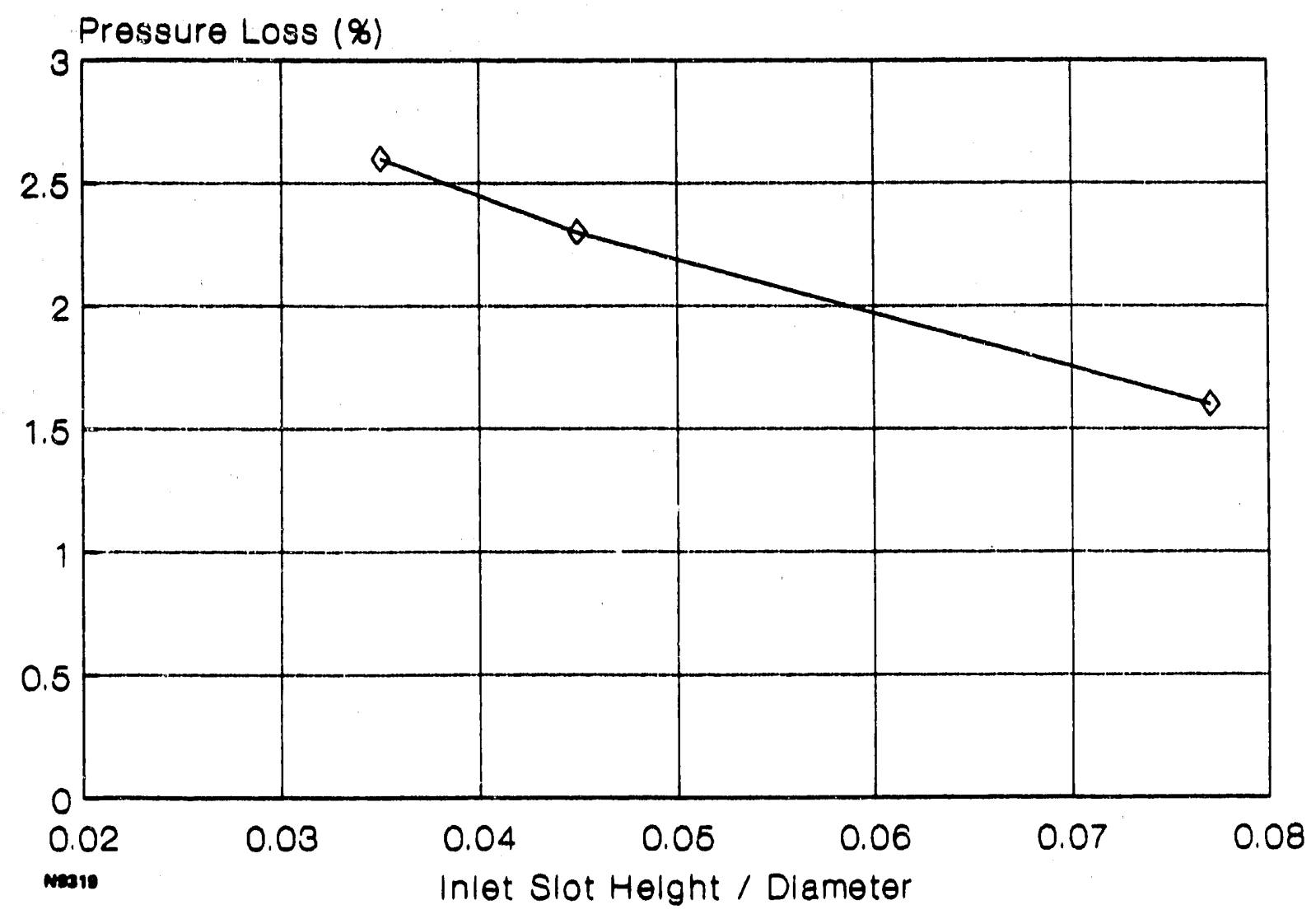

Figure 3-9 Pressure Drop at Design Mass Flow Rate as a Function of Air Inlet Slot Height 
of the inlet slot height. While the non-dimensional pressure drop (i.e. number of dynamic heads) decreases as the slot height is reduced, the dynamic head at the design mass flow rate increases. As the pressure drop scales as velocity squared, the net result is an increase in absolute pressure drop as the slot height is reduced. For the highest inlet velocities tested to date (i.e. the smallest slot height), the system pressure drop at the design mass flow rate is just over 2.5 percent, which would correspond to approximately 10" W.C. This is less than half the pressure drop of a conventional cyclone separator operated at the same inlet velocity.

\subsubsection{Water Addition Tests}

Preliminary water addition tests were made during this reporting period. The water was introduced via a single $0.125^{\prime \prime}$ OD stainless steel pipe located on axial centerline of CVS chamber close to the chamber wall. Preliminary observations were that a rotating sheet of water was indeed established in the CVS chamber and that this sheet appeared to pulse at some conditions. It was also noticed that though the bulk of the water exited the chamber as intended, some of the input water did exit the chamber via the clean gas exit tubes.

It was clear that the water entering the slotted central exit tube was doing so at either end, rather than along its length. The use of pulses of water as a flow visualization agent subsequently revealed that the loss mechanism was actually water flowing back into main chamber from water out-take chamber. (A stroboscopic light was also found to be a very useful aid in visualisation

of the two phase flow.) This mechanism is illustrated in Figure $3-10$. There is no direct loss of water from the chamber to the central exit tube. Rather, all the input water migrates inwards along the end-wall to the exit annulus, as intended. In the water out-take chamber, however, some of the water moves around 


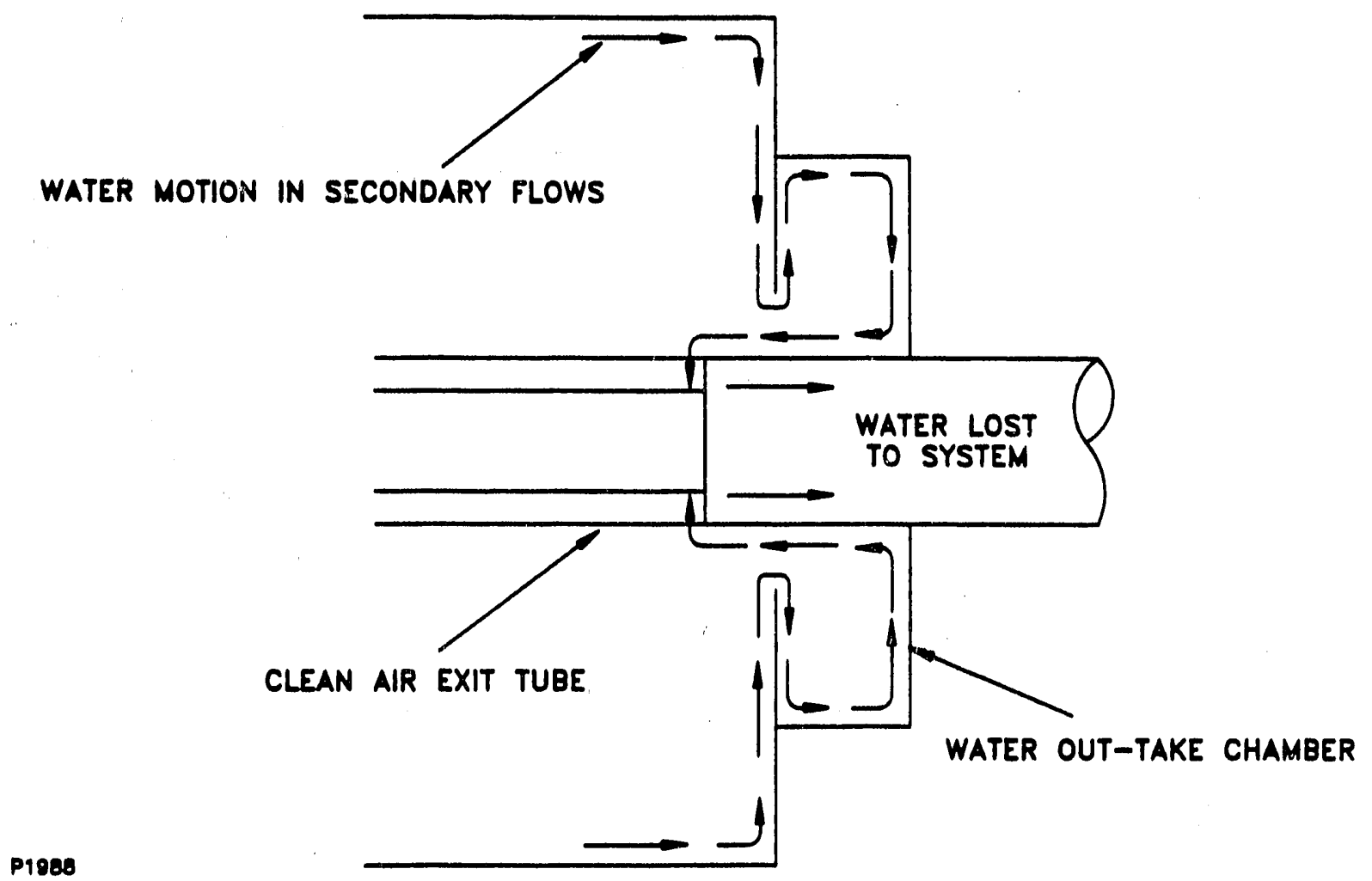

Figure 3-10 Water Loss Mechanism via Clean Gas Exit 
the outside wall of the chamber and reaches the outside of the central exit tube, where it spirals inwards back into the main chamber. When it reaches the beginning of the slotted section the water enters the slot and is lost.

Initial observations were that the rate of loss of water via the clean gas exit depended on both the water input flow rate and al so the air flow rate. This phenomenom will be investigated further in the next reporting period. 


\subsection{CONCLUSION AND PLANS FOR FUTURE WORK}

\subsection{CONCLUSIONS TO DATE}

Good technical progress has been made to date. A modular CVS was designed and constructed. The modular design allows for simple and rapid changes in air and water inlet and outlet geometries and chamber aspect ratio. Design and installation of the experimental hardware was completed. Shakedown testing indicated that only one small modification to the test arrangement was necessary. This modification was the removal from the air supply system of a shell and tube heat exchanger which had been installed to protect the acrylic CVS hardware from excessively high air temperatures.

The experimental hardware all operated as planned and air flows at and above the design mass flow rate were readily achieved. Early aerodynamic tests quickly demonstrated the superiority of the slotted exit tube over a more conventional vortex finder type exit. The vortex finder tube produced 50 percent higher pressure drops than the slotted exit at the same mass flow. The extremely beneficial effect on system pressure drop of the larger diameter exit tube was also quickly demonstrated. Further refinements in system design progressively reduced the device pressure drop to less than half that of a conventional reverse flow cyclone separator operating at the same inlet velocity.

Preliminary water addition experiments indicated that a sheet of water could indeed be established and contained within the chamber and that the proposed water removal mechanism via the chamber end-wall secondary flows was effective. However, some of the input water is being lost via the clean gas exit. The mechanism responsible for this loss is related to management of the 
water flow in the water out-take chamber and will be investigated in detail in the next reporting period.

\subsection{PLAN FOR NEXT REPORTING PERIOD}

* Run systematic water addition tests to quantify water loss via clean gas exits.

* Develop and test method(s) of eliminating water loss mechanism.

* Assess liquid containment performance.

* Characterize performance of alternate air inlet geometries

* Characterize performance of alternate chamber aspect ratio 


\subsection{REFERENCES}

Avco Research Laboratory, 1982, "A Novel Hot Gas Cleanup Device," Internal Research and Development Reports, Avco Research Laboratory, Everett, Massachusetts.

General Electric, 1980, Advanced Hot Gas Cleanup Concept Evaluation - Volume B: Developmental Cyclone Evaluation, US DOE FE-2357-39-B.

Lewellen, W. S., and Stickler, D. B., 1972, "Two Phase Vortex Investigation Related to the Colloidal Core Nuclear Reactor," ARL TR 72-0037, Aerospace Research Laboratory, Wright Patterson Air Force Base, Ohio.

Schmidt, P., 1986, "New Results in Cyclone Design, Especially for High Pressure and Temperature Application" in Gas Cleaning at High Temperatures, I.Chem. Eng. Symp. Ser. No. 99, pp. 67-72.

Smith, J. L., 1962, "An Analys is of the Vortex Flow in the Cyclone Separator", ASME Journal of Basic Engineering, 84, pp 602-608.

Stickler, D. B., Lakshmikantha, H., and Lewellen, W. S., 1974, "Heat Transfer and Containment Processes in Two Phase Cavity Nuclear Reactor," ARL TR 74-0007, Aerospace Research Laboratory, Wright Patterson Air Force Base, Ohio.

Yellott, J. I., and Broadley, P. R., 1955, "Fly Ash Separators for High Pressures and Temperatures," Industrial and Engineering Chemistry, 47, pp. 944-952. 

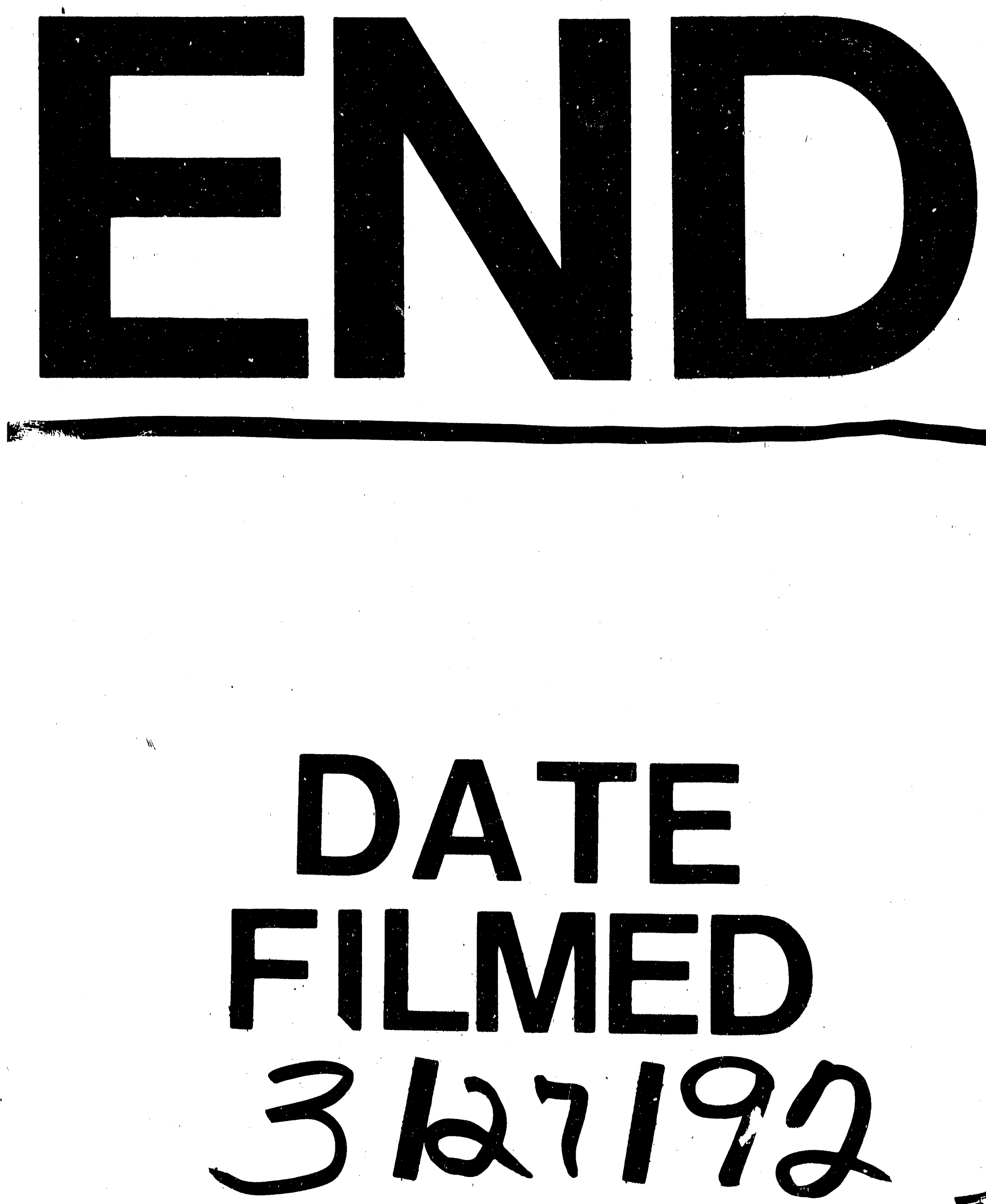
